EGU2020-16235

https://doi.org/10.5194/egusphere-egu2020-16235

EGU General Assembly 2020

(c) Author(s) 2020. This work is distributed under

the Creative Commons Attribution 4.0 License.

\title{
Regionalization of Vapor Pressure Deficit (VPD) in Spain
}

Miquel Tomas-Burguera ${ }^{1}$, Santiago Beguería Portugués ${ }^{1}$, Roberto Serrano-Notivoli ${ }^{1}$, and William Cabos $^{2}$

${ }^{1}$ Estacion Experimental de Aula Dei, ZARAGOZA, Spain (miquel.tomas@gmail.com)

${ }^{2}$ Department of Physics, University of Alcala, Madrid, Spain

Vapor Pressure Deficit (VPD) is an atmospheric variable that represents the extra water vapor that air may contain prior to condensation. It is a relevant variable for climatology due to its consideration as a measure of 'air dryness', but also for hydrology and ecohydrology. In spite of its relevance, studies focusing on VPD are scarce, especially when comparing with other variables such as temperature or precipitation. To obtain VPD values, temperature and air humidity data are required at the same time and location, which is difficult to obtain even in dense observational networks. While temperature is positively related with VPD, relative humidity shows a negative relation with VPD.

Within the framework of the CLICES Project, a spatial regionalization of VPD will be performed for mainland Spain. This project is focused on the climatic reconstruction of the last century and, for the most recent decades, data from a Regional Climate Model (RCM) simulation will be used as a complement of the observational data. Specifically, the climate of Spain for the period 1980-2017 at 3-hourly time step was simulated using REMO. Among a high amount of available methods, a bias correction procedure based on a quantile-quantile mapping in spatial coherent regions will be tested for the RCM correction. In order to implement this methodology, the VPD spatial regionalization is required and it will be addressed using a clustering methodology. Furthermore, regionalization of VPD will sharply improve our knowledge of this variable in Spain, a region showing high spatial contrasts affecting temperature, precipitation and wind speed. It is expected that the combination of the dissimilarities between temperature and precipitation will emerge in the regionalization of VPD values. 